\title{
Gabapentin in Burns
}

\author{
Nicholas Sheppard ${ }^{1, "}$ \\ ${ }^{1}$ Department of Plastic Surgery, Norfolk and Norwich University Hospital, Colney Lane, Norwich, UK \\ ${ }^{*}$ Corresponding author: Nicholas Sheppard, Department of Plastic Surgery, Norfolk and Norwich University Hospital, Colney Lane, Norwich, UK. Tel:+44-7980901395, E-mail: \\ nicholassheppard@nhs.net
}

Received: May 22, 2012; Accepted: June 21, 2012

Keywords: Burns; Pruritus; Gabapentin

\section{Dear Editor,}

I read with interest the article entitled Effect of Gabapentin on Morphine Consumption and Pain after Surgical Debridement of Burn Wounds: A Double-Blind Randomized Clinical Trial Study and was impressed by the scientific rigor and level of detailed observation. This is especially admirable in a study performed at the front line of burn surgery. Gabapentin appears to have a role to play in the reduction of pain and opiate usage during major burns surgery. It is worth, however, bringing the readers' attention to another key role for the drug in burn which is not mentioned in the discussion. Gabapentin also has an important role in the management of burn-induced itch. Evidence is emerging that it is more effective than conventional treatments such as antihistamines and should be considered a first-line treatment in burn patients (1). Taking this research on gabapentin in perioperative pain to the bedside and introducing gabapentin early in the treatment process for analgesia may help to prevent the transition from pain to itch that so frequently occurs during the healing process in these patients.

\section{Acknowledgements}

None declared.

\section{Financial Disclosure}

There is no financial disclosure.

\section{Funding/Support}

None.

\section{References}

1. Goutos I, Eldardiri M, Khan AA, Dziewulski P, Richardson PM. Comparative evaluation of antipruritic protocols in acute burns. The emerging value of gabapentin in the treatment of burns pruritus. J Burn Care Res. 2010;31(1):57-63.

Copyright (C) 2014, Kashan University of Medical Sciences; Published by Kowsar Corp. This is an open-access article distributed under the terms of the Creative Commons Attribution License, which permits unrestricted use, distribution, and reproduction in any medium, provided the original work is properly cited. 